\title{
Reflexões sobre os processos didático-pedagógicos na educação superior: para além da moda das metodologias ativas
}

\author{
Reflections on the didactic-pedagogical processes in higher education: beyond the \\ fashion of active methodologies
}

\author{
Francine de Paulo Martins Lima ${ }^{1}$ \\ Ronei Ximenes Martins ${ }^{2}$ \\ Helena Maria Ferreira ${ }^{3}$
}

\section{Resumo}

Este ensaio problematiza a adoção de Metodologias Ativas e da atuação docente na educação superior, a partir de discussão do aporte teórico que lhes dá base e de reflexões sobre o ensino e a aprendizagem. Para tal, nos valemos de literatura que aborda os conceitos de Aprendizagem Ativa, Didática, Formação do Professor e Inovação Educacional. Realizamos, também, um levantamento bibliográfico dos artigos e livros brasileiros sobre Metodologias Ativas, publicados entre 2015 e 2020. Discorremos sobre a origem conceitual do termo Metodologias Ativas, seu aporte teórico, o contexto sociocultural que interage com a premência de sua adoção. Analisamos o protagonismo docente e dos estudantes no contexto da aprendizagem ativa e criticamos suas formas de adoção quando realizadas sem reflexão e preparação da instituição educacional. Discutimos, também, as bases epistemológicas da docência e dos processos de ensino e de aprendizagem na perspectiva das aprendizagens ativas, que se configuram como uma questão do campo da Didática. Por fim, elencamos os desafios de um processo de ensino e de aprendizagem ativos e significativos, bem como destacamos elementos necessários para a ressignificação das ações de ensinar e de aprender na educação superior pós-moderna.

Palavras-chave: Processos de Ensino e de aprendizagem ativos. Inovação Educacional. Práticas Pedagógicas. Formação de Professores. Didática.

\footnotetext{
Abstract

${ }^{1}$ Doutora em Educação: Psicologia da Educação pela Pontifícia Universidade Católica de São Paulo - PUC-SP. Professora Adjunta da área de Didáticas e Estágios do Departamento de Educação e do Programa de Mestrado Profissional em Educação da Universidade Federal de Lavras - UFLA, Lavras, Minas Gerais, Brasil. E-mail: francine.lima@ufla.br

2 Doutor em Psicologia pela Universidade São Francisco. Docente Associado da área de Tecnologia e Educação do Departamento de Educação e do Programa de Mestrado Profissional em Educação da Universidade Federal de Lavras UFLA, Lavras, Minhas Gerais, Brasil. E-mail: rxmartins@ufla.br

3 Doutorado em Linguística Aplicada e Estudos da Linguagem pela Pontifícia Universidade Católica de São Paulo - PUCSP. Professora Associada da área de Linguística e ensino de línguas do Departamento de Estudos da Linguagem e do Mestrado Profissional em Educação da universidade Federal de Lavras - UFLA, Lavras, Minhas Gerais, Brasil. E-mail: helenaferreira@ufla.br
} 
This essay problematizes the adoption of Active Methodologies and the teaching performance in higher education, based on the discussion of the theoretical support that gives them basis and reflections about teaching and learning. To this end, we use literature that addresses the concepts of Active Learning, Didactics, Teacher Training, and Educational Innovation. We also use a bibliographic survey of Brazilian articles and books about Active Methodologies, that were published between 2015 and 2020. We discuss the conceptual origin of the term Active Methodologies, its theoretical contribution, the socio-cultural context that interacts with the urgency of its adoption. We analyze the role of teachers and students in the context of active learning and criticize their forms of adoption when carried out without reflection and preparation by the educational institution. We also discussed the epistemological bases of teaching and teaching-learning processes from the perspective of active learning, which is configured as a didactic issue. Finally, we list the challenges of an active and meaningful teaching and learning process, as well as highlighting elements necessary for the reframing of teaching-learning actions in postmodern higher education.

\section{Keywords:}

Active teaching and learning processes. Educational Innovation. Pedagogical practices. Teacher Education. Didactics.

\section{Introdução}

A preocupação com as questões didático-pedagógicas na educação superior não é recente e está longe de ser esgotada. Questões que cercam o ensinar e o aprender, bem como quais seriam os melhores métodos para um processo de ensino e de aprendizagem bem sucedido são pauta permanente no contexto da educação superior e nos levam a ponderar aspectos que se referem à moda das Metodologias Ativas.

Ressaltamos que a maioria dos professores da educação superior, dada constituição histórica da docência neste nível de ensino, adentra os ambientes de ensino por meio da sua condição de especialista de uma determinada área profissional, ou ainda, por consequência do seu percurso acadêmico no campo da pesquisa. Aspectos referentes à formação docente nem sempre são valorizados como importantes para o exercício de uma atividade docente competente e responsável.

Ao lado disso, é necessário considerar que, no processo de produzir conhecimentos durante a graduação, o fazer pedagógico envolve dimensões de ensino, de pesquisa e de extensão, integrados e articulados. Tal perspectiva pressupõe o rompimento com a fragmentação disciplinar e o currículo baseado unicamente nos arranjos de disciplinas. 
Assim, faz-se necessário superar a lógica de atuação docente baseada no ensino prescritivo de conteúdos que, em alguns momentos, na visão dos estudantes, parecem distanciados dos objetivos da formação profissional que escolherem.

Em uma perspectiva de superação dessa realidade e considerando os requisitos da atualidade, universidades/faculdades buscam desenvolver ações que viabilizem uma formação profissional que articule ensino, pesquisa e extensão, resultando em uma fusão entre as dimensões técnica, social e humana dos futuros graduados, corroborando a ideia de que a atitude profissional deve ser técnica, ética, responsável e conectada com as demandas da sociedade.

Nesse sentido, a ação docente, pilar da atividade educacional, ganha destaque na medida em que tem a responsabilidade de assegurar formação técnica e humana para o exercício profissional. Ocorre que a ação docente depende integralmente de sua interação com a ação do aprendente e para que o processo de ensino-aprendizagem se dê com efetividade é necessário compreender o contexto sociocultural que o envolve.

Entendemos, portanto, que há estreita relação entre a qualidade de ensino na universidade e a qualidade da formação profissional do docente e, mais especificamente, com o trabalho docente desenvolvido no dia a dia da sala de aula, pois a qualidade está diretamente ligada aos processos de ensino, que em articulação com a pesquisa e a extensão, podem promover processos mais qualitativos de aprendizagem.

Nesse sentido, impõe-se a necessária superação da desarticulação entre os processos de ensino e de aprendizagem, ainda presentes nas práticas de muitos docentes no contexto do ensino superior. Do distanciamento entre quem ensina e quem aprende, como se ensina e como se aprende e, também, as razões pelas quais se aprende.

Nesse contexto e com o intuito de superar o distanciamento do ensino com as demandas dos estudantes, as universidades/faculdades passaram a consumir propostas de inovação da prática pedagógica, geralmente associadas ao uso massivo de recursos educacionais digitais. Entretanto, considerando que o processo de produzir conhecimento científico nos instiga a duvidar de "fórmulas mágicas", faz-se necessário refletir criticamente sobre as certezas da adoção das chamadas Metodologias Ativas como solução para os 
crescentes problemas da apatia dos estudantes em relação aos processos de ensino, da elevação da evasão e das contínuas trocas de cursos ou de faculdade.

Assim, o objetivo deste ensaio é apresentar reflexões sobre os processos didáticopedagógicos na educação superior pós-moderna, à luz da pretensa hegemonia da adoção das chamadas Metodologias Ativas como solução de problemas no ensino superior brasileiro.

Como percurso metodológico, fizemos assunção por uma perspectiva teórica, constituída por dois momentos basilares: 1) levantamento bibliográfico dos artigos e livros brasileiros sobre Metodologias Ativas, publicados entre 2015 e 2020; e 2) discussão teóricoanalítica de conceitos relacionados às bases epistemológicas da docência e dos processos de ensino e de aprendizagem na perspectiva das aprendizagens ativas, que se configuram como uma questão didática. Além disso, foram discutidas questões relevantes para a ressignificação das ações de ensinar e de aprender na educação superior.

\section{Ensino superior na modernidade líquida: o palco da aprendizagem ativa}

Vivemos em um mundo muito diferente daquele em que foi modelado nosso sistema educacional. Constituído ao longo de séculos, tal sistema tem como uma de suas premissas, ainda hoje, a presença do professor e do estudante, juntos, no lugar onde um vai ensinar e o outro aprender. Por outro lado, a sociedade se adapta rapidamente aos avanços oferecidos, principalmente, pelas tecnologias digitais de informação e comunicação (TDIC). Autores como Lévy (1999), Bauman (2001) e Castells com colaboradores (2016) discutiram profundamente os fenômenos sociais e culturais relacionados às influências das TDIC na pósmodernidade e dão sustentação para tal constatação.

Os construtos da cibercultura (LÉVY, 1999), da sociedade da informação (CASTELLS, 1999) e da modernidade líquida (BAUMAN, 2001) trouxeram luz sobre educação no contexto da pós-modernidade. Para Bauman (2001), nosso tempo histórico é caracterizado pelas relações sociais efêmeras, uma modernidade "leve" e "fluida". Lévy (1999) elaborou, a partir da ideia de que estamos um dilúvio informacional que inunda as 
vidas de todos os humanos, o conceito de ciberespaço ${ }^{4}$. Mesmo aqueles que não têm acesso às TDIC que dão suporte ao ciberespaço estão mergulhados nele. É também no ciberespaço que se constituiu uma nova cultura, na visão de Lévy: a cibercultura. Ela explica as dinâmicas sociais e econômicas que emergiram do advento das tecnologias digitais. Nesse contexto surgiram também dois novos fenômenos sociais: a exclusão provocada pelas tecnologias e o surgimento de um novo tipo de identidade.

Para Giddens (2002) a identidade não é algo definitivo. Trata-se de processo contínuo de (re)construção. A globalização e a cibercultura romperam com as relações tradicionais de trabalho, sociais, familiares, simbólicas e afetivas. A ausência de geolocalização e de relações prolongadas, caracterizadas, por exemplo, pela permanência por muitos anos em um mesmo local de moradia e de trabalho, deixou de ser um valor reconhecido (GIDDENS, 2002). A sociedade da informação e a modernidade líquida influenciaram fortemente a identidade da geração nascida entre os anos 1990 e 2000. Chamados de Millennials, são contemporâneos ao advento da internet e vivem imersos na sociedade da informação e na modernidade líquida. São pessoas predominantemente conectadas e suas relações sociais e familiares estão associadas ao uso de smartphones e computadores. Pois bem, os millennials chegaram à universidade. Este cenário socioeconômico e cultural complexo pressiona os sistemas educacionais institucionalizados para mudanças estruturais e curriculares, fato que impulsiona a adoção de inovações nas práticas pedagógicas dos docentes universitários.

Nesse contexto, as instituições educacionais têm enfrentado o desafio de (re)criar ambientes de ensino e ao mesmo tempo de geração de novos conhecimentos, visto que a fluidez que vivenciamos impõe confrontos constantes com o que é desconhecido. Toda instituição educacional é instada a ser, ao mesmo tempo, locus do presente e do futuro. Tal movimento se intensificou na última década e os termos Inovação Pedagógica e Metodologias Ativas passaram dominar as discussões nos ambientes de gestão acadêmica e de políticas públicas.

Entretanto, a adoção de pretensas inovações, desprovida de análise profunda do contexto e acrítica em relação aos seus efeitos, pode gerar resultados indesejados e até

\footnotetext{
${ }^{4}$ Meio de comunicação gerado pela interconexão mundial dos computadores e que especifica não apenas a infraestrutura material da comunicação digital, mas também o universo oceânico de informação que ela abriga e os humanos que navegam e alimentam esse universo (LEVY, 1999)
}

Revista Devir Educação, Lavras, vol.2, n.4, p.149-169 jul./dez., 2020. 
contribuir para deterioração da relação dos estudantes com os estudos, com os professores e com a instituição de educação superior. Para compreender melhor a complexidade envolvida na adoção de inovações pedagógicas e de metodologias consideradas novas no cotidiano da comunidade acadêmica, faz-se necessário o aprofundamento teórico-conceitual do significado das Metodologias Ativas.

Considerando que um dos requisitos para a busca por bibliografia qualificada é a identificação de descritores padronizados (Thesaurus ${ }^{5}$ ) relacionados aos conceitos-chave do tema em investigação, buscamos verificar se o termo Metodologia(s) Ativa(s) é descritor padronizado. A constatação é de que, apesar de amplamente utilizado, ele não consta no Thesaurus Brasileiro de Educação ${ }^{6}$ e, no âmbito internacional, também não há equivalentes em inglês nos Thesaurus UNESCO ${ }^{7}$ e ERIC ${ }^{8}$. Esses Thesaurus são referências mundiais para a área de educação.

Depois de analisarmos os descritores internacionais relacionados ao tema, identificamos Active Learning como referência. Aprendizagem Ativa é, portanto, o termo mais adequado para caracterizar conceitualmente o deslocamento da ênfase do processo de ensino, centrado na figura de um professor que detém o conhecimento, para processos distribuídos, de forma equânime, na comunidade aprendente composta por professor e estudantes. Esse deslocamento, constatamos, é cerne da caracterização das denominadas Metodologias Ativas. Constatamos, também, que a utilização de Active Methodologies, tradução literal do termo em português, se constitui descritor limitado quando se busca produção internacional sobre o tema. Assim, recomendamos a utilização de Active Learning como palavra-chave para buscas em bases internacionais.

Active Learning, segundo Bonwell e Eison (1991), se refere a um conjunto de técnicas de ensino que permitem aos estudantes participar de atividades de aprendizagem, assumindo a responsabilidade e o protagonismo do próprio aprendizado. É qualquer processo que leve os estudantes a fazer e pensar sobre o que estão fazendo. De acordo com Gogus (2011), a aprendizagem ativa é mais focada no desenvolvimento cognitivo do que na aquisição de fatos

\footnotetext{
5 thesaurus é um repositório que organiza descritores padronizados a partir de estruturas conceituais previamente estabelecidas, destinados à indexação e à recuperação de documentos e informações de determinado campo do saber.

${ }^{6}$ http://inep.gov.br/thesaurus-brasileiro-da-educacao

${ }_{7}^{7}$ http://vocabularies.unesco.org/browser/thesaurus/en/

${ }^{8}$ https://eric.ed.gov/?
}

Revista Devir Educação, Lavras, vol.2, n.4, p.149-169 jul./dez., 2020. 
e transmissão de informações. O papel dos estudantes não é ser um ouvinte passivo e anotador de informações, mas envolvido ativamente com seus estudos.

Bonwell e Eison (1991), cuja obra é referência para a definição da aprendizagem ativa, destacaram que apesar da aparição frequente na literatura (já na década de 1990), o carece de uma origem identificável ou de uma definição comum. Segundo Gogus (2011), a aprendizagem ativa às vezes é remetida ao Método Socrático (estilo de ensino de Sócrates) em que se apresenta um problema e se direciona a discussão em torno dos pontos-chave relacionados ao problema para permitir que os estudantes descubram/elaborem as respostas/resoluções do problema e do conteúdo, evitando exposições e palestras.

Ainda segundo Gogus, a aprendizagem ativa emergiu dos trabalhos de John Dewey (1858-1952) que, a partir de precedentes históricos do Construtivismo, desenvolveu argumentos sobre a necessidade de as escolas deixarem as memorizações repetitivas e rotineiras e passarem a se engajar no ensino prático do mundo real para permitirem o desenvolvimento de conhecimentos por meio da criatividade e colaboração. Dewey utilizou pela primeira vez o termo aprendiz ativo em 1924, a fim de enfatizar o aprendizado como processo ativo no qual os alunos constroem seu próprio significado e que o aprendizado ocorre por meio de reflexão e do pensamento crítico.

Como a denominação Metodologias Ativas é amplamente utilizada no Brasil, realizamos busca por artigos e livros que tratam do tema no mecanismo Google Acadêmico, para produções entre 2015 e 2020 com esse descritor, a fim de identificarmos referências bibliográficas direcionadas para a discussão teórico-conceitual que dá base a sua aplicação. Para a busca ampliada, com o termo tanto no título quanto no conteúdo de artigos e livros, foram encontradas 16.200 referências. Na busca do termo exclusivamente no título, foram encontradas 1.090 referências, corroborando a percepção de que há premência do tema no contexto educacional atual. Em ambas as buscas, os trabalhos mais citados (30 ou mais citações) são os apresentados no Quadro 1.

Quadro 1 - Artigos e Livros sobre Metodologias Ativas publicados entre 2015 e 2020 e que apresentam o número de citações maior que 30

\begin{tabular}{|c|c|}
\hline Título & Número de \\
\hline
\end{tabular}

Revista Devir Educação, Lavras, vol.2, n.4, p.149-169 jul./dez., 2020. 


\begin{tabular}{|l|r|}
\hline & citações \\
\hline $\begin{array}{l}\text { Mudando a educação com metodologias ativas. (MORAN, } \\
\text { 2015). }\end{array}$ & 502 \\
\hline $\begin{array}{l}\text { Metodologias ativas para uma educação inovadora: uma } \\
\text { abordagem teórico-prática. (BACICH; MORAN, 2018). }\end{array}$ & 158 \\
\hline $\begin{array}{l}\text { Os princípios das metodologias ativas de ensino: uma abordagem } \\
\text { teórica. (DIESEL; BALDEZ; MARTINS, 2017). }\end{array}$ & 88 \\
\hline $\begin{array}{l}\text { Metodologias ativas de ensino-aprendizagem: revisão integrativa. } \\
\text { (PAIVA et al, 2016). }\end{array}$ & 79 \\
\hline $\begin{array}{l}\text { Metodologias ativas para uma aprendizagem mais profunda. } \\
\text { (MORAN, 2018). }\end{array}$ & 56 \\
\hline $\begin{array}{l}\text { Metodologias ativas de ensino/aprendizagem: dificuldades de } \\
\text { docentes de um curso de enfermagem. (MESQUITA; } \\
\text { MENESES; RAMOS, 2016). }\end{array}$ & 28 \\
\hline $\begin{array}{l}\text { Metodologias ativas: das concepções às práticas em distintos } \\
\text { níveis de ensino. (VALENTE; DE ALMEIDA; GERALDINI, } \\
\text { 2017). }\end{array}$ & \\
\hline
\end{tabular}

Fonte: Google Acadêmico - busca realizada em 28/03/2020

Observamos que o autor mais referenciado é José Manuel Moran. Em seus trabalhos, as Metodologias Ativas são abordadas, em consonância com a definição de Active Learning, como conjunto de métodos, técnicas, recursos e suas formas de aplicação. Entretanto, a perspectiva teórico-conceitual é eminentemente pragmática, prevalecendo a busca de justificativas para a sua adoção a partir da utilidade e das necessidades de atendimento às demandas da pós-modernidade. Segundo Moran (2015)

precisamos adotar metodologias em que os alunos se envolvam em atividades cada vez mais complexas, em que tenham que tomar decisões e avaliar os resultados [...]. Se queremos que sejam criativos, eles precisam

Revista Devir Educação, Lavras, vol.2, n.4, p.149-169 jul./dez., 2020. 
experimentar inúmeras novas possibilidades de mostrar sua iniciativa" (p.17).

Babich e Moran (2018) contrastam as metodologias ativas com as metodologias predominantes no ensino, denominando-as de dedutivas, pois o professor transmite primeiro a teoria e depois o aluno deve aplicá-la em situações mais específicas.

Moran (2015) e Diesel, Baldez e Martins (2017) concordam que a origem das Metodologias Ativas está nas propostas de John Dewey e apontam como antecedentes históricos as teorias de Lev Vygotsky (1896-1934) - aprendizagem pela interação social, Jerome Bruner (1915-2016) e David Ausubel (1918-2008) - aprendizagem significativa. Também apontam que é possível identificar a perspectiva de Paulo Freire (1921-1997) para autonomia.

Sintetizando, a proposta de Aprendizagem Ativa se propõe a permitir que os estudantes meditem e exerçam controle sobre o aprendizado, engajando-se em interações sociais significativas com outros aprendentes, com professores e com conteúdos curriculares. O papel do professor, nessa perspectiva, passa a ser o de promotor e mediador de interações, colaboração, reflexão, experimentação, interpretação e construção.

Concordamos que as bases teóricas para sustentação do que se convencionou chamar Aprendizagem Ativa são as apontadas por Gogus, Moran e Diesel, Baldez e Martins, citados anteriormente, e destacamos a relevância conceitual da autonomia no processo, visto que sem ela nenhum protagonismo se constitui. Além disso, chamamos a atenção para o necessário distanciamento do protagonismo do estudante com o não-diretivismo de Carl Rogers (19021987), visto que, ao contrário da generalização apressada presente nos discursos do senso comum sobre o tema, o centro do processo de ensino não se transfere do professor para o estudante.

Consideramos que o protagonismo deva ser compartilhado pela comunidade aprendente, que envolve docente e estudantes. Portanto, a Aprendizagem Ativa (ou Metodologias Ativas) se constitui a partir de estratégias de ensino que necessitam muito mais do que meios e recursos tecnológicos para aplicação bem sucedida. Nesse ponto, somos críticos da visão eminentemente pragmática e da falsa dicotomia entre Teoria e Prática, presentes em justificativas para a adoção das Metodologias Ativas, quais sejam, as de que promovem "rompimento com o modelo tradicional [...com] integração entre teoria e prática" (PAIVA et al., 2016, p.152).

Revista Devir Educação, Lavras, vol.2, n.4, p.149-169 jul./dez., 2020. 
Os argumentos até aqui apresentados oferecem elementos suficientes para afirmarmos que o termo Metodologias Ativas, ao contrário de Aprendizagem Ativa, é vazio de significado, posto que a atividade aprender e ensinar se dá no âmbito das interações internas ao processo, protagonizadas por estudantes e professores e que as metodologias utilizadas para proporcionar tal atividade, por si, não são ativas ou passivas.

Isso posto, destacamos que antes que se escolha utilizar métodos de ensino tais como Flipped Classroom, Peer Instruction, Problem Based Learning, Project Based Learning, é necessário que docentes, estudantes e equipe gestora se preparem, do ponto de vista da formação, para o rompimento com o modelo convencional de ensino superior. Se deve superar, por exemplo, a cultura do tempo de ensino dividido em aulas cronometradas (e.g. 50 minutos); a fragmentação de conhecimentos em áreas disciplinares; a seriação ou modularização de currículos disciplinares; os sistemas de avaliação que buscam identificar se os estudantes conseguem repetir o que lhes foi "transmitido"; às exigências injustificadas para os dias atuais (tais como a de frequência obrigatória em 75\% das atividades presenciais); as intromissões de conselhos profissionais na formação acadêmica oferecida pelas faculdades.

Portanto, é pré-requisito que o currículo se desloque da organização baseada em um amontoado de conteúdos disciplinares para uma que seja interdisciplinar e/ou transdisciplinar de conhecimentos, que levem à aprendizagem de conceitos pré-concebidos e de aplicação prática, mas também de processos, de vivências, de realidades factuais, de fenômenos materiais e imateriais que se interligam para gerar competências e valores culturais.

Nesse ponto, cabe retomar o contexto sociocultural em que se insere a decisão de adotar a Aprendizagem Ativa como centro da organização curricular da instituição de ensino superior. Apesar do termo Tecnologias Digitais de Informação e de Comunicação acompanhar as "Metodologias Ativas" e ser aplicado frequentemente como referência à técnicas e artefatos digitais, é necessário que se reflita sobre elas a partir de uma conceituação mais abrangente. Ao considerarmos o recorte de meios técnicos para viabilização de métodos de aprendizagem ativa, não podemos afastar a faceta ideológica conectada às tecnologias, ou seja, as dimensões organizacionais, políticas e sociais, além das instrumentais e técnicas (VIEIRA PINTO, 2005). Portanto, não é possível falar em TDIC para aprendizagem ativa sem considerar os aspectos ideológicos embutidos na tecnologia, ou seja, da não neutralidade seu na sociedade, bem como dos ganhos e, ao mesmo tempo, dos efeitos adversos e 
prejudiciais de sua utilização, como alertam diversos autores, entre os quais Buckingham (2008) e Carr (2010).

Outro conceito que merece reflexão é o de inovação, muito repetido como precursor de novas práticas de ensino na educação superior. O termo inovação assume diferentes sentidos, relacionados aos múltiplos olhares e a partir de diferentes aplicações. Messina (2001) considera que a inovação se estabelece pela alteração de sentido a respeito da prática corrente, mas com caráter intencional, sistemático e planejado, em oposição às mudanças espontâneas ou esporádicas. A autora alerta que o termo, em educação, é utilizado também para justificar propostas conservadoras, homogeneizar políticas e práticas e promover propostas repetidas que não consideram a diversidade sociocultural dos contextos passíveis de alteração. Ou seja, é preciso cuidado com o discurso da inovação educacional que, no fundo, gera mudanças para que tudo permaneça como antes. Consideramos tal alerta especialmente cabível quando se adota a Aprendizagem Ativa como "inovação pedagógica" restrita a mudanças pontuais na atuação de docentes e de reformas em salas de aula, decoradas para que sejam mais agradáveis, coloridas e cheias de parafernália eletrônica. Nesses casos, quando se olha de perto o que professores e estudantes estão fazendo, verifica-se que estão dançando a mesma e velha música tradicional, em novo palco.

Para vencer os desafios específicos da educação superior na sociedade da informação e na modernidade líquida, é necessário se ter em mente seu papel transformador da sociedade. Sem foco na reflexão, na crítica e na produção de novo conhecimento, a formação universitária se reduz à replicação do estado das coisas, funcionando como mera preparadora de trabalhadores, mesmo que seja oferecida com uma roupagem mais agradável aos jovens. Freire (2015) alerta para a necessidade de a prática de ensinar necessitar das relações humanos-humanos a ponto de construir uma educação para o homem-sujeito.

Destacamos, portanto, a necessária atenção que deve ser dada ao desenvolvimento da autonomia do estudante. Paiva et al. (2016), ao realizarem revisão bibliográfica sobre as metodologias ativas, verificaram que a Autonomia é enfatizada em todos os artigos que analisaram. Pode-se compreender, portanto, que o desenvolvimento da autonomia é questão central no processo de aprendizagem ativa. Este e outros aspectos relacionados aos processos de ensino e aprendizagem ativos serão abordados a seguir. 


\section{A busca por processos de ensino e de aprendizagem ativos: contribuições do campo da Didática}

Apesar de ser notório que os processos de ensino e de aprendizagem são interligados e apresentam uma relação de interdependência, é comum observarmos uma dissociação entre esses processos na realização das práticas pedagógicas, no contexto do ensino superior. Trata-se de uma questão do campo da Didática antiga e que requer a superação da compreensão reducionista acerca do que venha a ser a relação ensino e aprendizagem na formação de adultos.

A Didática, como área de conhecimento que se ocupa, notadamente, da reflexão sistemática acerca dos processos de ensino e de aprendizagem, bem como da relação professor e estudante (CANDAU, 2004), se preocupa com os processos pedagógicos que se delineiam e se desenvolvem no contexto da sala de aula, considerando os modos de ensinar de forma detida. A Didática se envolve, também, com a discussão sobre os processos de formação profissional do professor, considerando as nuances sociais, políticas, culturais e econômicas que envolvem todo o processo pedagógico. Assim, muitos dos desafios existentes em situações de ensino e de aprendizagem são de ordem didática, os quais necessitam serem superados e/ou minimizados.

Entre os desafios existentes, na atualidade, está a busca por processos de ensino e de aprendizagem ativos, compreendidos de forma integrada e relacional entre os sujeitos envolvidos, em uma perspectiva de construção coletiva do conhecimento, o qual não se dá a priori, mas essencialmente na dialogicidade entre os sujeitos do processo de ensino e de aprendizagem (FRANCO, 2012), considerando as dimensões humana, técnica e político social inerentes ao fazer pedagógico (CANDAU, 2004).

Assim, tanto o estudante quanto o professor são sujeitos ativos e protagonistas e, ao se relacionarem no processo de ensinar e de aprender, assumem responsabilidades, interações e níveis de implicação com a elaboração do conhecimento de forma distinta.

Nesse sentido, uma prática pedagógica implicada com a qualidade da formação e com a autonomia do estudante pressupõe a busca por metodologias e práticas que superem os reducionismos ainda presentes no ato de ensinar. Se serão inovadoras ou não, dependerão da estrutura e da forma como tais práticas e metodologias se inserirem no contexto institucional. Messina (2001) destaca que há diferença entre processos de inovação educacional que são 
determinados por autoridades ou políticas externas ao contexto das escolas e aquelas que nascem no seio da instituição ou, muitas vezes, na sala de aula, e que se propagam por adesão natural.

Entendemos que práticas pedagógicas inovadoras pressupõem as situações didáticopedagógicas que favorecem e qualificam a elaboração do conhecimento pelo estudante de forma contextualizada, considerando ações diversificadas em que haja a implicação do graduando de forma direta com o objeto de conhecimento, assegurando-lhe o protagonismo, ao mesmo tempo em que se valoriza e reconhece a essencial atuação do professor na promoção da aprendizagem, em um ambiente institucional que favoreça e valorize esta forma de ação docente. Nessa direção, inovação da prática pedagógica se refere a estratégias organizadas de forma sistemática utilizadas para introduzir ou provocar mudanças de atitudes, formas de compreensão, ideias, conteúdos e modelos de práticas pedagógicas (MASETTO, 2018).

Nosso foco, neste ponto, se volta para o professor. Ao lado do necessário planejamento e da inovação na gestão educacional, é preciso redimensionar a ideia de professor como transmissor do conhecimento (STRAUSS, 2001) e de estudante passivo. A retórica desenfreada, ainda muito presente na ação de universitários, assim como a utilização de metodologias tidas como salvadoras, importadas em situações de modismos pedagógicos e que geralmente são replicadas de forma impensadas, estão em xeque, principalmente, a partir do inconformismo e do olhar crítico dos estudantes.

Para que ocorra o protagonismo do estudante, é preciso o protagonismo também na ação do professor, traduzido na elaboração de boas provocações e estratégias, mobilizadoras da aprendizagem. A fim de destacar a ressignificação da prática pedagógica, consideramos necessário trazer à tona a discussão sobre o ato de ensinar e sobre o papel do professor na busca pelo redimensionamento dos processos de ensino e de aprendizagem ativos. Para tanto, trataremos, a seguir, da especificidade do ensinar e do aprender de forma articulada e situada no contexto das salas de aula do ensino superior.

Em relação a isso, Roldão (2005) destaca que os professores são necessários como agentes de qualidade da educação, ressaltando a importância de se tornarem profissionais do ensino, com estatuto pleno, no sentido de especialistas na organização da apreensão e construção do saber por outros. Para a autora, o que caracteriza o ofício do professor é o ensino ou "fazer com que o outro aprenda", ação que "[...] requer um vasto conjunto de 
saberes científicos, no campo da educação, e está longe de ser espontânea ou resultar automaticamente do domínio do conteúdo a ensinar" (p. 117). Para ela, o saber enquanto caracterizador do ato de ensinar deve ser percebido em sua totalidade, de modo que seja assegurado o saber propriamente educacional que, além de configurar a especificidade do docente, lhe permite "[...] mobilizar modos de agir entre saber conteudinal e sua apropriação pelos aprendentes para que com eles construam conhecimento novo" (p.117).

Essa tarefa é desafiadora e exige discussão e reflexão do coletivo envolvido no processo de formação oferecido pela instituição, de modo que reafirme o sentimento de pertencimento a um corpo profissional. Requer, também, permanente reflexão acerca das mudanças no contexto social e do modo com que estas afetam as instituições de ensino, mais especificamente, o estudante e o professor, bem como a relação que estes estabelecem com a constituição e elaboração dos novos saberes. Por fim, necessita articulação dos saberes da prática com os saberes teórico-científicos, bem como a clarificação dos conhecimentos/saberes específicos necessários à prática docente.

Como bem define Roldão (2005), a especificidade distintiva da função docente é o ensinar, o que supõe a necessária existência de conhecimentos específicos para isso, a investigação e o questionamento da prática pedagógica, a articulação entre currículo, didática e o conhecimento das especificidades do estudante e das formas de aprendizagem. Supõe promover situações e estratégias que viabilizem e mobilizem a aprendizagem do outro em uma nova perspectiva da prática pedagógica, o que por sua vez convoca a mudança de postura e de mentalidade frente ao fazer docente. Requer a ressignificação do papel do professor e o entendimento do lugar que tanto docente quanto estudante ocupam na elaboração e desenvolvimento do conhecimento.

Compreendemos, assim, que ser professor supõe o domínio de múltiplos conhecimentos reconhecendo a ação de ensinar como uma ação complexa, fundada em um domínio seguro de um saber e em competências específicas que não podem ser desenvolvidas apenas empiricamente, por meio do fazer diário (ROLDÃO, 2007). Evidenciamos que a compreensão do conhecimento que se aprende e se exerce na prática deve ser fundada numa prática informada, alimentada por um conhecimento formal, teórico, investigado e discutido com os pares e com todos os envolvidos no processo educativo.

Nessa perspectiva, para que a inovação metodológica seja possível é necessário que o professor problematize e reflita sobre alguns pontos: (a) Quais são as teorias e as crenças que 
conduzem o seu entendimento de educação, de ensino, de aprendizagem e de avaliação; (b) Qual o meu entendimento de aula, da sua organização e da relação professor-aluno; (c) Quais são os desafios que cercam a minha docência no ensino superior; (d) Qual é a ideia de formação profissional dá suporte à ação docente desenvolvida; (e) Qual é o lugar que o estudante ocupa na sala de aula, no processo de aprendizagem, quais as suas necessidades e como me relaciono com ele; (f) Quais as possibilidades de mudança no modo com que os conteúdos de ensino são abordados ou ainda as estratégias para a aprendizagem pelo estudante; (g) Quais os métodos e técnicas podem melhorar os processos de ensino; (h) Qual é o lugar da formação técnica e qual é a sua interlocução com a formação humana, eticamente comprometida com a sociedade.

A busca por respostas às questões elencadas no parágrafo anterior indica a possibilidade de se reexaminar a prática desenvolvida e o entendimento de que inovar requer mudança de postura, requer clareza dos desafios com os quais nos depararemos e a busca pela superação deles. Requer, também, uma postura docente ativa frente ao processo de ensinar e todas as nuances que o envolve. Situa o ensino de forma aproximada e interdependente do processo de aprendizagem e do estudante, uma vez a prática pedagógica comporta essencialmente questões que se referem ao o que ensinar; para quem ensinar e como ensinar, reexaminado e evidenciando as dimensões humana, político-social e técnica da ação didática.

Trata-se do gradativo desenvolvimento de um raciocínio pedagógico, termo cunhado por Lee Shulman (1987) ao tratar da base do conhecimento do professor. Para Shulman (1987), a base do conhecimento envolve sete conhecimentos específicos, reforçando a ideia de que não basta saber o conteúdo a ser ensinado, é preciso saber ensinar, o que pressupõe um conjunto de conhecimentos para uma prática pedagógica exitosa. São eles: a) conhecimento do conteúdo a ser ensinado; b) da pedagogia geral, o qual refere-se aos conhecimentos elaborados por estudiosos da educação, considerando os princípios e estratégias de gestão e organização da sala de aula e sua relação com o currículo; c) conhecimento do currículo, diretamente relacionado com os materiais e programas que dão suporte a ação docente; d) do conhecimento pedagógico do conteúdo, o que pressupõe o domínio no âmbito da pedagogia, domínio exclusivo de professores; e) conhecimento dos alunos e suas especificidades; f) conhecimento dos contextos educacionais, associados ao entendimento do funcionamento da turma, da sala de aula, da gestão e comunidade; e, por fim, g) conhecimento dos objetivos, metas e valores educacionais e de seus condicionantes e fundamentos filosóficos e históricos. 
Para Shulman (1987), o ensino ocorre a partir do processo de raciocínio que, de forma sistemática, realiza-se por um ato de razão, depois de raciocínio e de reflexão, que culmina em uma nova postura que novamente é reexaminada e ressignificada em um movimento de raciocínio pedagógico. Assim, o processo de ensino é tido como compreensão e raciocínio; transformação e reflexão.

Diante do exposto, o raciocínio pedagógico revela-se essencial para o desenvolvimento e promoção de processos ativos de ensino e de aprendizagem, pois pressupõe a implicação do professor na qualificação de um ensino comprometido com a promoção da aprendizagem do estudante, que por sua vez também desempenha um papel de relevância na manipulação e aproximação com o conteúdo e sua relação com contextos que extrapolam a sala de aula e aproximam-se do uso social do conteúdo objeto de aprendizagem.

Isso posto, reforçamos que a dimensão didática do processo de raciocínio pedagógico e da relação é, necessariamente, interativa e implicada entre professor e estudante, cuja confiança e parceria amistosa passam a fazer-se cada mais presente. Nessa direção, terminologias como empatia e acolhimento passam a figurar no processo de ensinoaprendizagem, fazendo emergir a dimensão humana, comumente diminuída nos processos pedagógicos no ensino superior em função da supervalorização do conteúdo, ao lado da dimensão técnica e político-social.

Na medida em que essa aproximação do professor com o estudante se dá pela reflexão e elaboração do conhecimento, abre-se espaço para a potencialização dos processos de raciocínio pedagógico e, portanto, de ampliação de espaços de protagonismo pelo estudante que, esclarecido dos objetivos e formas possíveis de se aprender dado conteúdo, vê-se envolvido e disposto elaborar ou reelaborar o conhecimento. Aos poucos, a atitude de protagonismo do estudante - aprendizagem ativa - vai se desenvolvendo, sob a mediação, apoio e provocação do docente, uma vez que é o discente quem dá sentido ao conteúdo, a si e aos outros, de forma a situar a relação do conhecimento consigo mesmo e com o mundo. Afinal, "é o sujeito que aprende (ninguém pode fazê-lo em seu lugar), mas ele só pode aprender pela mediação do outro (frente a frente ou indiretamente) e participando da atividade" (CHARLOT, 2005).

Em suma, seja qual for a metodologia ou caminhos escolhidos para o desenvolvimento do conteúdo, independentemente da área de conhecimento, um processo de ensinoaprendizagem ativo e atraente parte da premissa da contextualização do saber; do 
compromisso com a elaboração do conhecimento de forma partilhada e dialogada; da implicação do professor com a aprendizagem do estudante; das boas provocações feitas aos estudantes para desejarem aprender; da tomada de consciência pelo graduando da responsabilidade que possui no percurso formativo; da crença de que a boa aula se constrói com o estudante e não apenas para ele.

\section{Considerações Finais}

Embora seja um espaço de ampla e sistematizada produção de conhecimentos, a educação superior apresenta limitações relacionadas à prática pedagógica em função da especialidade dos campos de conhecimento e tecnociências relacionadas a cada área de formação profissional, bem como do perfil dos discentes, que, recorrentemente, possuem experiências escolares de características de passividades.

Desse modo, abordamos o contexto do surgimento e do desenvolvimento da aprendizagem ativa, que se constituiu no início dos anos 1990, mas que ganhou relevância nas/pelas discussões sobre a modernidade líquida. Este cenário socioeconômico e cultural complexo traz demandas para os sistemas educacionais institucionalizados, o que impele a busca de mudanças estruturais e curriculares, fato que impulsiona a adoção do que se convencionou serem inovações das práticas pedagógicas. No entanto, é recorrente a adoção de pretensas inovações, sem uma adequada análise do contexto e sem uma crítica em relação aos seus efeitos. A partir dessa questão, consideramos relevante a tarefa proposta neste texto, qual seja, o aprofundamento teórico-conceitual do sentido das metodologias ativas, seguido de uma discussão acerca da aprendizagem ativa, o que nos permite ressignificar os processos de ensinar e de aprender.

Assim, procedemos a uma revisão bibliográfica, que abarcou o descritor Metodologia(s) Ativa(s). Nesse percurso analítico, consideramos que a expressão "Active Learning" (Aprendizagem Ativa) é a mais adequada para caracterizar conceitualmente a interação necessária aos processos de ensino e de aprendizagem. Ao revistarmos tais pesquisas, vislumbramos como características reiteradas a responsabilização e o protagonismo dos aprendizes em relação ao próprio aprendizado.

No entanto, em função da recorrência da expressão metodologias ativas, fizemos opção por uma busca com a utilização desse descritor, o que nos permitiu compreender que as bases conceituais dessa questão não são novidade, uma vez que Dewey e Freire já faziam assunção 
por esses modos de ensinar e de aprender. Além disso, constatamos que as metodologias, por si, não são ativas ou passivas, são os sujeitos - professores e alunos - que assumem a própria ação de aprender e de ensinar.

Nesse contexto, abordamos também o conceito de inovação - muito caro à discussão aqui proposta - que não se sucumbe ao uso de tecnologias em sala de aula, mas que abrange uma ressignificação de concepções e dos modos de se concretizar os processos de ensino e de aprendizagem. Nesse bojo, reiteramos a relação de interdependência entre ensinar e aprender como princípio basilar para a Didática contemporânea, o que suscita investimentos não somente nos modos de ensinar, mas também nos processos de formação profissional do professor e nos desafios que precisam ser minimizados na tarefa de educar. Assim, merecem destaque a construção coletiva do conhecimento, o desenvolvimento da autonomia e a mudanças de concepções e atitudes.

No contexto do ensino superior, uma prática inovadora pressupõe um sentimento de pertencimento a um corpo profissional, uma permanente reflexão acerca das teorias, das metodologias, das mudanças no contexto social e de suas influências no processo educativo, reconhecimento dos conhecimentos prévios dos alunos e de suas relações como os novos conhecimentos/saberes. Assim, é demandada uma ressignificação do papel do professor e do aluno, abarcando questões como o que ensinar, para que ensinar e como ensinar, bem como o que aprender, para que aprender e como aprender, reexaminado e evidenciando as dimensões humana, político-social e técnica da ação didática. Esse contexto faz emergir o conceito de raciocínio pedagógico, que culmina em uma nova postura que retroalimenta os processos de ensinar e de aprender.

Por fim, salientamos que a formação continuada de professores ocupa um papel primordial, pois favorece a discussão e o aprofundamento de temáticas que podem favorecer a ressignificação da docência pelo professor universitário. É o momento de reavaliar posturas, dialogar sobre novas teorias e se aprofundar naquelas que já dão suporte à ação docente. As ações formativas devem ter como foco as necessidades formativas dos docentes frente às demandas apresentadas por uma nova geração de estudantes: conectados; com acesso às mais diversificadas formas de comunicação e informação, mas ao mesmo tempo, com certa dificuldade no gerenciamento e compreensão das informações e na elaboração do conhecimento. As velhas e "tradicionais" aulas não atendem mais as necessidades dos novos alunos.

Revista Devir Educação, Lavras, vol.2, n.4, p.149-169 jul./dez., 2020. 


\section{Referências}

BACICH, L.; MORAN, J. Metodologias ativas para uma educação inovadora: uma abordagem teórico-prática. São Paulo: Penso Editora, 2018.

BAUMAN, Z. Modernidade líquida. Rio de Janeiro: Zahar, 2001.

BONWELL, C. C.; EISON, J. Active learning: Creating excitement in the classroom (ASHE-ERIC Higher Education Report n. 1) Washington. DC: George Washington University, 1991.

BUCKINGHAM, D. (Ed.). Youth, identity, and digital media. Cambridge, MA: MIT Press, 2008.

CANDAU, V. (Org.) A Didática em questão. Rio de Janeiro: Vozes, 2004.

CARR, N. The shallows: what the internet is doing to our brains. Nova York: WW Norton \& Company, 2011.

CASTELLS, M. A. Era da Informação: economia, sociedade e cultura, v. 3, São Paulo: Paz e Terra (1999).

CASTELlS, M.; FERNANDEZ-ARDEVOL, M.; LINCHUAN QIU, J.; SEY, A. Mobile Communication and Society: a global perspective. MIT Press: Cambridge, Massachusetts, 2016.

CHARLOT, B. Relação com o saber, formação dos professores e globalização: questões para a educação hoje. Porto Alegre: Artmed, 2005.

DIESEL, Al.; BALDEZ, A. L. S.; MARTINS, S. N. Os princípios das metodologias ativas de ensino: uma abordagem teórica. Revista Thema,Pelotas , v. 14, n. 1, p. 268-288, 2017. Disponível em: http://revistathema.ifsul.edu.br/index.php/thema/article/view/404. Acesso em: 10 de maio de 2020.

FRANCO, M.A. R. S. Pedagogia e prática docente. São Paulo: Cortez, 2012.

FREIRE, P. Pedagogia da autonomia: saberes necessários à prática educativa. Rio de Janeiro, Paz e Terra, 2015.

GOGUS, A. Active Learning. In: N. M. Seel (Ed.). Encyclopedia of the Sciences of Learning. Springer Science \& Business Media, 2011.

LÉVY, P. Cibercultura. São Paulo: Editora 34. (Tradução de Carlos Irineu da Costa),1999. 
MASETTO, M. T. Trilhas abertas na universidade: inovação curricular, práticas pedagógicas e formação de professores. São Paulo: Editora Summus, 2018.

MESSINA, G. Mudança e Inovação Educacional: notas para reflexão. Cadernos de Pesquisa, São Paulo, n. 114, p. 225-233, 2001 Disponível em: https://www.scielo.br/pdf/cp/n114/a10n114.pdf . Acesso em: 15 de abril de 2020.

MESQUITA, S. K. C.; MENESES, R. M. V.; RAMOS, D. K. R.. Metodologias ativas de ensino/aprendizagem: dificuldades de docentes de um curso de enfermagem. Trabalho, Educação e Saúde, Rio de Janeiro, v. 14, n. 2, p. 473-486, 2016. Disponível em: https://www.scielo.br/pdf/tes/v14n2/1678-1007-tes-1981-7746-sip00114.pdf. Acesso em: 10 de maio de 2020.

MORÁN, J. Mudando a educação com metodologias ativas. Coleção Mídias Contemporâneas. Convergências Midiáticas, Educação e Cidadania: aproximações jovens, v. 2, p. 15-33, 2015

MORAN, J. Metodologias ativas para uma aprendizagem mais profunda. In: MORAN, J. Metodologias ativas para uma educação inovadora: uma abordagem teórico-prática. Porto Alegre: Penso, 2018. p. 02-25.

PAIVA, M. R. F.; PARENTE, J. R. F.; BRANDÃO, I. R.; QUEIROZ, A. H. B. Metodologias ativas de ensino-aprendizagem: revisão integrativa. Sanare -Revista de Políticas Públicas, Sobral, v. 15, n. 2, p. 1-9, 2016.

ROLDÃO, M. C. Profissionalidade docente em análise - especificidades do ensino superior e não superior. Revista Nuances: estudos sobre a educação, Presidente Prudente, Ano XI; v.12, n.13, jan./dez. p.106-126, $2005 . \quad$ Disponível em: https://revista.fct.unesp.br/index.php/Nuances/article/view/1692/1601. Acesso em: 15 de agosto de 2019.

ROLDÃO, M. C. Função docente - natureza e construção do conhecimento profissional. Revista Brasileira de Educação, Rio de Janeiro v.12, n. 34, p. 94-103, 2007. https://doi.org/10.1590/S1413-24782007000100008.

STRAUSS, S. Folk psychology, folk pedagogy and their relations to subject matter knowledge. In B. Torff and R. J. Sternberg (Eds.), Understanding and teaching the intuitive mind Mahwah, NJ: Erlbaum, p. 217-242, 2001

SHULMAN, L. Knowledge and teaching: foundations of the new reform. Harvard Education Review, Cambridge, v. 57, n.1, p.1-22, 1987.

VALENTE, J. A.; ALMEIDA, M. E. B.; GERALDINi, A. F. S. Metodologias ativas: das concepções às práticas em distintos níveis de ensino. Revista Diálogo Educacional, Curitiba v. 17, n. 52, p. 455-478, 2017. doi: http://dx.doi.org/10.7213/1981-416X.17.052.DS07,

VIEIRA PINTO, A. O conceito de tecnologia. Rio de Janeiro: Contraponto, 2005. 
Recebido em: 06/11/2020

Aprovado em 20/11/2020

Revista Devir Educação, Lavras, vol.2, n.4, p.149-169 jul./dez., 2020. 